\title{
Investigation of air gasification of micronized coal, mechanically activated using the plasma control of the process
}

\author{
Evgenii Butakov $^{l *}$, Anatoly Burdukov ${ }^{l}$, Mikhail Chernetskiy ${ }^{l, 2}$, and Victor Kuznetsov ${ }^{2}$ \\ ${ }^{1}$ Kutateladze Institute of Thermophysics, SB RAS, Novosibirsk, Russia \\ ${ }^{2}$ Siberian Federal University, Krasnoyarsk, Russia
}

\begin{abstract}
Combination of the processes of coal combustion and gasification into a single technology of mechano-chemical and plasmachemical activation is of a considerable scientific and technological interest. Enhancement of coal reactivity at their grinding with mechanical activation is associated with an increase in the reaction rate of carbon material, and at plasma-chemical effect, the main is an increase in reactivity of the oxidizing agent caused by the high plasma temperatures of atomic oxygen. The process of gasification was studied on the 1-MW setup with tangential scroll supply of pulverized coal-air mixture and cylindrical reaction chamber. Coal ground by the standard boiler mill is fed to the disintegrator, then, it is sent to the scroll inlet of the burner-reactor with the transport air. Pulverized coal is ignited by the plasmatron of $10-\mathrm{kW}$ power. In experiments on air gasification of micronized coal, carried out at the temperature in the reaction chamber of $1000-1200^{\circ} \mathrm{C}$ and air excess $\alpha=$ $0.3-1$, the data on $\mathrm{CO}$ concentration of $11 \%$ and $\mathrm{H}_{2}$ concentration of up to $6 \%$ were obtained. Air and air-steam gasification of mechanically-activated micronized coals with plasma control was calculated using SigmaFlow software package.
\end{abstract}

\section{Introduction}

Coal is the energy fuel of the main resource both in our country and worldwide, so its effective use is certainly relevant from both the economic and ecological points of view. Enhancement of energy efficiency of its use, i.e., reduction of its consumption per production of an energy unit, is of a particular importance.

Combination of the processes of coal combustion and gasification into a single technology of mechano-chemical and plasma-chemical activation is of a considerable scientific and technological interest. Enhancement of coal reactivity at their grinding with mechanical activation is associated [1-3] with an increase in the reaction rate of carbon material, and at plasma-chemical effect [4], the main is an increase in reactivity of the oxidizing agent caused by the high plasma temperatures of atomic oxygen.

\footnotetext{
*Corresponding author: e butakov@mail.ru
} 
Due to an increase in the chemical activity of coals at their grinding with mechanical activation [5], determined at IT SB RAS, it is possible to develop the efficient burners on pulverized coals, whose parameters are close to the gas-oil installations. Thus, it becomes possible to develop the systems of pulverized coal gasification in the flow of mechanicallyactivated micronized coals with gasification parameters, which are considerably higher than the currently used ones. When developing the coal gasification system on micronized coal, the use of plasma-energy installations seems urgent to run the installations and regulate the thermal process. Since the problem of efficient use of coal as the energy fuel for the traditional thermal power technologies and gasification processes for the combined-cycle plants and synthesis gas production for gasification of settlements and industries are of the great interest; the relevance of the problem and research is unquestionable.

\section{Experimental apparatus and procedure}

To study the single-stage gasification process, the second stage of two-stage reactor with tangential scroll supply of coal-air suspension and cylindrical reaction chamber was used. Coal of DR grade with maximal amount of volatiles from Kuznetsk deposit (one of the main coal deposits of Siberia) was used in experiments. The technical composition of coal is as follows (mass \%, dry): moisture $\mathrm{W}_{\mathrm{rl}}-19.0$, ash $\mathrm{A}_{\mathrm{r}}-14.3$, volatile content - 43.5, sulfur $\mathrm{S}_{\mathrm{dl}}-0.30$, high heat value $\mathrm{Q}_{\mathrm{daf}}-7327 \mathrm{kcal} / \mathrm{kg}$. Ground coal is fed to the disintegrator; then, it is fed by an ejector with transport air to the scroll burner. Pulverized coal is ignited by a low-power plasmatron $(\mathrm{N} \sim 10 \mathrm{~kW})$. Coal consumption is $17 \mathrm{~kg} / \mathrm{h}$, it is controlled by the voltage sensors of the feeders on the basis of preliminary calibration. Gas composition along the reaction chamber is measured by the optical-absorption gas analyzer at three points; temperature is measured in the same cross-sections of the chamber by the platinumplatinum-rhodium thermocouples.

The thermal setup of 1-MW power for coal combustion and gasification is shown in Fig. 1; location of temperature sensors and gas analyzers along the setup is presented in Fig. 2. Coal, ground in the standard boiler mill, is supplied by the feeder to the disintegrator; then, it is fed with transport air to the scroll inlet of the reactor-burner.

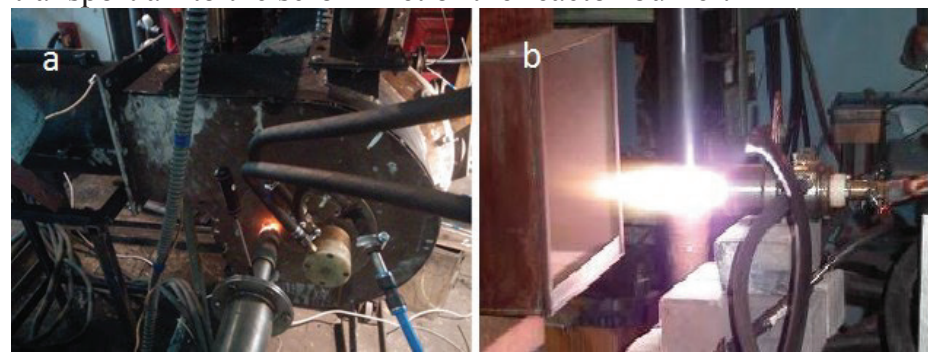

Fig. 1. a) Thermal 1-MW setup with plasma control of the process; b) Plasmatron during operation

Numerical simulation of the turbulent flow of an incompressible liquid in the volume of the burner used Reynolds equations with consideration of interfacial interaction. Reynolds equations were closed by means of the two-parameter model of turbulence: the standard k- $\varepsilon$ model. To describe the processes of particle motion, the Lagrange method is used. The particle motion is described by equations of material point dynamics with consideration of resistance and gravity. Flow turbulence at particle motion is taken into account by introduction of random fluctuations of gas velocity into equation of motion for particles. The solution of radiative transfer equation is based on P1 approximation of the method of spherical harmonics for the gray two-phase two-temperature medium. The process of coal particle combustion is considered as the following successive stages: evaporation of 
moisture from the fuel, escape and combustion of volatile components, and combustion of coke residue [6]. Mechanical activation of coals is accounted by adding the multistage character of chemical reactions with partial overlapping of stages to the mathematical model. At that, the kinetic constants are taken from TGA data for mechanically activated coals [7]. Plasma activation of coal dust and formation of an additional plasma heat source are considered as an internal heat source with heat release characteristic of the plasmatron power. This source is an energy contribution of the electric arc. The model is supplemented with formation of the source terms for the gas components during the passage of carbon residue through the high-temperature region of a plasma jet. In addition to gasification reactions, chemical reactions of carbon, characteristic of plasma activation of coal, are taken into account. This model is implemented in the package CFD SigmaFlow applications [8].

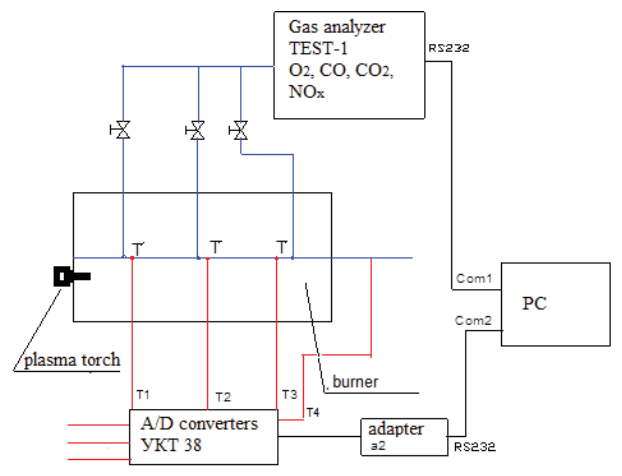

Fig. 2. Layout of temperature sensors and receiving probes of gas composition control.

\section{Results and discussion}

Experiments were carried out with the constant consumption of fuel: $17 \mathrm{~kg} / \mathrm{h}$ at air excesses of $0.3 ; 0.4 ; 0.6 ; 1.0$, and $35.7 ; 47.6 ; 71.4 ; 119 \mathrm{~m}^{3} / \mathrm{h}$ and plasmatron power of 10 $\mathrm{kW}$.

During the entire experiment, the maximal temperature in the center of reaction chamber was $1250{ }^{\circ} \mathrm{C}$; at that, the temperature after the tangential scroll inlet did not exceed $750{ }^{\circ} \mathrm{C}$. The temperature at the end of the reaction chamber was $1000{ }^{\circ} \mathrm{C}$. The temperature does not depend on variations of the air flow rates, i.e., after pulverized coal ignition and beginning of stable combustion of the coal-dust flame, the time of pulverized coal particle stay in the chamber decreases with a change in the flow velocity, and this compensates the heat release growth with an increase in $\alpha$ in the chamber volume and does not lead to a significant increase in the flow temperature. This effect influences a change in $\mathrm{CO}$ concentration due to the reaction of $\mathrm{CO}$ reducing because the latter requires more time in comparison with the reaction of carbon oxidation, which occurs with a high rate.

It is necessary to note that oxygen concentration in the chamber at all $\alpha$ is close to zero, i.e., oxygen is consumed completely at all stages of combustion. Depending on the coefficient of air excess, concentration of carbon oxide varied within $12-15 \%$, and concentration of hydrogen varied within $7.5-10 \%$, and $\mathrm{CO}$ concentration decreases with an increase in $\alpha$, and hydrogen concentration increases; at that, with an increase in $\alpha, \mathrm{CO}_{2}$ concentration decreases from 12 to $10 \%$. These effects relate to temperature changes and time of pulverized coal stay in the reaction chamber. 


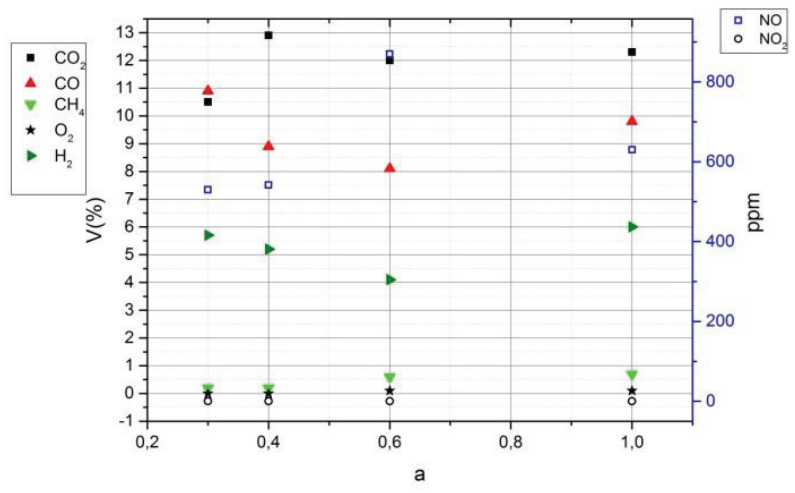

Fig. 3. Gas composition at air gasification of mechanically-activated micronized coals with plasma control of the process (plasmatron power - $10 \mathrm{~kW}$; coefficient of air excess - 1, 0.6, 0.4, 0.3;)

Using calculations have been carried out Air and air-steam gasification of mechanically activated micronized coal with plasma control of the process was calculated using the SigmaFlow software package. The complex mathematical model was adapted by the data of experimental studies based on gasification of coal fuel, ground in the disintegrator at the excess air coefficient of 0.6 . It can be seen (Table 1) that there is a satisfactory agreement with experimental results.

Table 1. Gas composition at the outlet of the second stage chamber at air excess coefficients $\alpha=0.6$

\begin{tabular}{|c|r|r|r|r|r|r|}
\hline Gas composition (vol. \%) & $\mathrm{CH}_{4}$ & $\mathrm{CO}$ & $\mathrm{H}_{2}$ & $\mathrm{H}_{2} \mathrm{O}$ & $\mathrm{CO}_{2}$ & $\mathrm{~N}_{2}$ \\
\hline Experimental data & 0.5 & 8 & 4 & - & 12 & - \\
\hline Volumetric data & 0.6 & 6.3 & 3.1 & 9 & 15 & 66 \\
\hline
\end{tabular}

Results of numerical studies on the effect of plasmatron presence on coal dust gasification are shown in Table 2. The plasmatron was taken into account out by addition of a plasma heat source in the form of an internal heat source with heat release characteristic of plasmatron power of $10 \mathrm{~kW}$. According to calculation results, plasma activation of mechanically activated coal fuel improves gas composition at the outlet. CO concentration increases from 31.7 to $33 \%$, and hydrogen concentration rises from 8.9 to $10.5 \%$.

Table 2. Gas composition at the outlet of the second stage chamber at excess air coefficients $\alpha=0.3$ with plasma heat source of $10-\mathrm{kW}$ power

\begin{tabular}{|c|c|c|c|c|c|c|}
\hline Gas composition (vol. \%) & $\mathrm{CH}_{4}$ & $\mathrm{CO}$ & $\mathrm{H}_{2}$ & $\mathrm{H}_{2} \mathrm{O}$ & $\mathrm{CO}_{2}$ & $\mathrm{~N}_{2}$ \\
\hline Air gasification & 4.9 & 31.7 & 8.9 & 1.3 & 1.7 & 51.5 \\
\hline $\begin{array}{c}\text { Air gasification with } \\
\text { plasmatron }\end{array}$ & 4.4 & 33 & 10.5 & 0.8 & 1.5 & 49.8 \\
\hline
\end{tabular}

\section{Conclusion}

In experiments on air gasification of micronized coal, carried out at $750-1200^{\circ} \mathrm{C}$ and air excess $\alpha=0.3-1$ in the reaction chamber, first data on CO concentration of up to $11 \%$ and $\mathrm{H} 2$ concentration of up to $6 \%$ were obtained.

The complex mathematical model was adapted by the experimental results on air and air-steam gasification of micronized coals, mechanically activated at plasma control of the 
process. Satisfactory agreement of calculation and experimental data on gasification of coal fuel, ground in the disintegrator, is shown.

The run of setup using the plasmatron was tested for the first time as well as introduction of a plasma jet into the reaction chamber for controlling the thermal conditions of gasification process. Due to computational studies, it was shown that plasma activation of mechanically activated coal fuel improves composition of generator gas at the outlet.

The work was financially supported by the Russian Ministry of Education and Science, according to Subsidiary Agreement No. 14.613.21.0005 (unique project identifier RFMEFI61314X0005).

\section{References}

1. M.Yu. Chernetskiy, A.P. Burdukov, E.B. Butakov, I.S. Anufriev, P.A. Strizhak, Combustion, Explosion, and Shock Waves, 52, 3, 326-328 (2016)

2. A.P. Burdukov, E.B. Butakov, V.I. Popov, M.Y. Chernetskiy, N.S. Chernetskaya, Thermal Science, 20, 23-33 (2016)

3. A.P. Burdukov, V.I. Popov, G.V. Chernova, M.Yu. Chernetskiy, A.A. Dekterev, N.S. Chernetskaya, V.M. Markova, V.N. Churashev, T.S. Yusupov, Thermal Engineering, 60, 889-894 (2013)

4. V.E. Messerle, A.B. Ustimenko, Y.E. Karpenko, M.Y. Chernetskiy, A.A. Dekterev, S.A. Filimonov, Thermal Engineering, 62, 442-451 (2015)

5. A.P. Burdukov, V.I. Popov, M.Yu. Chernetskiy, A.A. Dekterev, K. Hanjalić, Applied Thermal Engineering, 74, 174-181 (2014)

6. M. Yu. Chernetskiy, A. A. Dekterev, Combustion, Explosion, and Shock Waves, 47, 3, 280-288 (2011)

7. M.Yu. Chernetskiy, A.A. Dekterev, A.P. Burdukov, K. Hanjalić, Fuel, 135, 443458 (2014)

8. M.Yu. Chernetskii, A.N. Alekhnovich, A.A. Dekterev, Thermal Engineering, 59, 610-618. (2012) 